\title{
Circumcision with Intravenous (IV) Ketamine, Thiopentone and Penile Block: A Safe and Cost-effective Anesthetic Technique
}

\section{Akhter Hossain Loban ${ }^{1 *}$ \\ Millat-E-Ibrahim ${ }^{1}$ \\ Jahanara Alauddin ${ }^{1}$ \\ KMN Ferdous ${ }^{2}$}

${ }^{1}$ Department of Anesthesiology, Dhaka Shishu (Children) Hospital, Dhaka

${ }^{2}$ Department of Pediatric Surgery, Dhaka Shishu (Children) Hospital, Dhaka

Conflict of interest: None Source of funding: None

\section{*Correspondence to:}

\section{Dr Akhter Hossain Loban}

Department of Anaesthesiology, Dhaka Shishu (Children) Hospital, Dhaka

E-mail: lobanakhter@yahoo.com

Mobile: +88 01711544983

\section{How to cite this article:}

Loban AH, Ibrahim ME, Alauddin J, Ferdous KMN. Circumcision with intravenous (IV) ketamine, thiopentone and penile block: a safe and cost-effective anesthetic technique. Chatt Maa Shi Hosp Med Coll J 2013; 12(1): 34-37.

\begin{abstract}
Background: Circumcision is a common minor surgical procedure among Muslim and Jews population. Both surgeon and guardian want safe but low-cost anesthesia for this procedure. Sometimes parents do not agree to anesthetize their child for this purpose. Using penile block with IV ketamine and thiopentone sodium (TPS), patients can be managed smoothly without any major complication and it is a costeffective technique. Objective: This study was designed to perform safe and costeffective anesthetic management for circumcision of children. Materials and Methods: This is an observational prospective study carried out in Dhaka Shishu Hospital and Dhaka Central Hospital during the period of January to December 2011. Total 336 cases of circumcision were done. Children with American Society of Anesthesiologists (ASA) Grades I \& II, between 1 and 12 years of age were selected for this study. Patient was sedated using Ketamine $1 \mathrm{mg} / \mathrm{kg}$ plus TPS $2.5 \mathrm{mg} / \mathrm{kg}$. Then penile block was given. Close observation and monitoring was done clinically as well as with the help of pulse oximeter and sphygmomanometer. Results: Among 336 patients no cases of laryngospasm, cynanosis, vomiting and convulsion was observed. Cough developed in 7 cases, slight fall of $\mathrm{SpO}_{2}$ in 10 cases and subcutaneous hematoma in 11 cases were noted. Incomplete block occurred in 5 cases, urethral puncture in cases and accidental injection in corpus cavernosum in 2 cases. Approximate average total cost for anesthesia procedure per case was 3.5 USD only. Conclusion: Circumcision with low dose intravenous Ketamine and TPS with penile block is a safe and cost-effective anesthetic technique.

Key words: Circumcision; Penile block; Ketamine; TPS; Bupivacaine; Lignocaine.
\end{abstract}

\section{INTRODUCTION}

Circumcision is the most common minor surgical procedure among Muslim and Jews. Light sedation and penile block is the easiest and safest type of anesthesia in this operation. Patient is not usually admitted in hospital, so early smooth recovery is essential. There are relatively few indications for regional techniques as the sole method in pediatric patients. The chief advantage of regional blockade in an infant or child is profound pain relief postoperatively. This advantage is particularly true in ambulatory surgery patients, in whom narcosis, with the resulting drowsiness and possible nausea, may delay discharge. ${ }^{1}$ Regional block in combination with sedation or light general anesthesia is preferred because it provides excellent analgesia extending to the postoperative period. 
The sensory nerve of penis is dorsal nerve of the penis which is derived from inferior pudendal nerve. The nerve lies on each side of midline below the buck's fascia against dorsal surface of the corpus cavernosum, supplies distal two-third of the skin of penis (Figure 1). Dorsal penile nerve block may not completely block all the pain of circumcision. ${ }^{2}$ So, to block the total sensation of prepuce posterior scrotal branches of perineal nerve which run para-urethrally to the ventral surface supplying the frenum is to be blocked too. ${ }^{3}$ Patient should be sedated and made pain free before injecting local anesthetics for penile block. Regarding safety, dorsal penile nerve block is much safer than caudal block as we do not have to interfere with axial nerve.

\section{MATERIALS AND METHODS}

The prospective study was carried out in Dhaka Shishu (Children) Hospital, at Sher-e-Bangla Nagar, Dhaka and Central Hopsital at Dhanmondi, Dhaka. We included all the patients between the age group of 1 to 12 years. Patients with full stomach and having respiratory tract infection were excluded. All the patients were fed nothing orally and kept empty stomach 3-4 hours prior to the operation.

First, IV cannula was inserted in all patients, then ketamine $(1 \mathrm{mg} / \mathrm{kg})$ and atropine $(0.02 \mathrm{mg} / \mathrm{kg})$ were injected slowly so that there was no apnoea or fall in $\mathrm{SpO}_{2}$. Injection thiopentone sodium (TPS) $(7.5 \mathrm{mg} / \mathrm{kg})$ was taken in a syringe, one-third was injected to prevent unusual movement induced by ketamine. Then penile block was given using local anesthetic agent after skin preparation. Local anesthetic agents used were $0.5 \%$ bupivacane plus $2 \%$ lignocaine with a total volume of $4-5 \mathrm{cc}$. To block dorsal nerve of penis, $2.5 \mathrm{~cm}$ needle $(23 \mathrm{G}$ ) was inserted in the midline $1 \mathrm{~cm}$ above the base of the penis. About 1-1.5 cc local anesthetic was injected on each side below buck's fascia at 10.30 and $1.30 \mathrm{O}^{\prime}$ clock position. ${ }^{4}$ Another $2 \mathrm{cc}$ of local anesthetics was injected ventrally over the urethra subcutaneously. Among these age groups, all patients have infantile type of penis, so dose requirement of local anesthetic agent is almost same. Gentle pressure was maintained using a gauge to prevent swelling and distal movement of local agents. Another onethird of TPS was injected if patient moved or opened their eyes during operation. Rest of the TPS was given before the patient was moved to postoperative ward. TPS was given very slowly, so that patient does not develop apnoea or respiratory depression. Then, patient was observed clinically and with pulse oximeter for any complication of drugs used as intravenous agents (Ketamine and Thioipentone sodium) and local anesthetic agents (bupivacaine and lignocaine).

\section{RESULTS}

During the study period of 1 year a total number of 336 patients were circumcised between the ages of 1 year 3 months to 11 years 8 months. Mean age was 3.9 years. Maximum patients were between the age of $1-5$ years. The weight of the study population ranged from $11.2 \mathrm{~kg}$ to $56 \mathrm{~kg}$. Mean weight was $13.4 \mathrm{~kg}$. Highest numbers of patients were between $10-20 \mathrm{~kg}$ weight (Tables $1 \& 2$, Figure 2).

Some local and systemic complications like subcutaneous hematoma, incomplete block, urethral puncture, accidental injection in corpus cavernosum, cough and slight fall of $\mathrm{PaO}_{2}$ were observed in few patients, which were managed accordingly. But no patient developed laryngospasm, cyanosis or convulsion (Table 3).

Average total cost of anesthetic agents was 3.5 USD (range: 3-4.5 USD) per case.

Table 1: Age distribution $(N=336)$

\begin{tabular}{lcc}
\multicolumn{1}{c}{ Age } & Number & Percentage \\
1-5 yrs & 151 & 44.95 \\
$5-10$ yrs & 145 & 43.15 \\
Above 10 yrs & 40 & 11.9 \\
Total & 336 & 100 \\
Mean age: 3.9 years & & \\
\hline
\end{tabular}

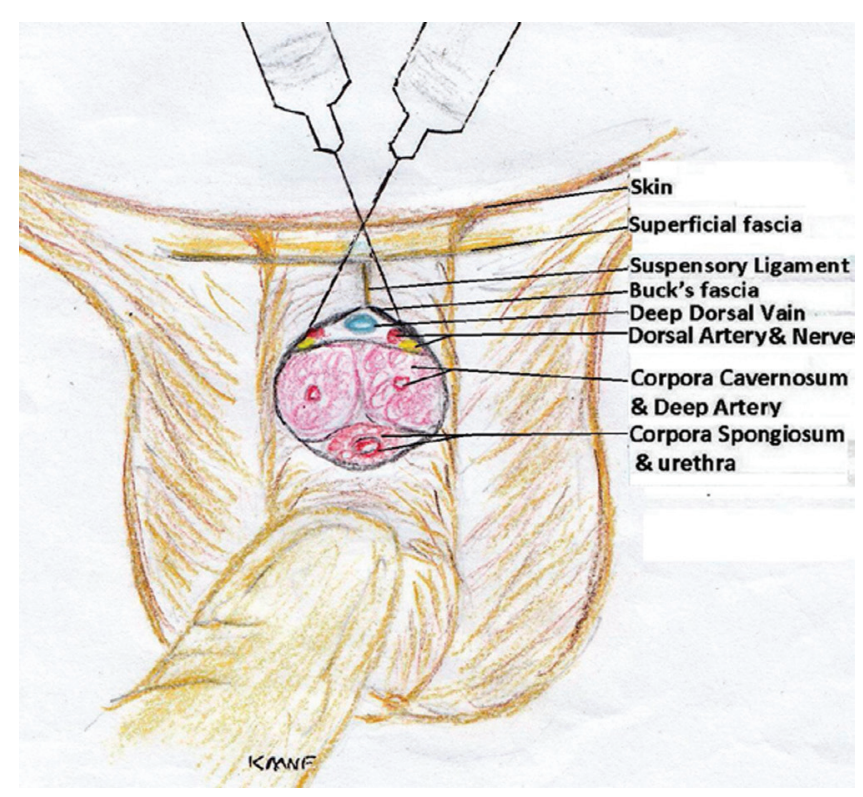

Figure 1: Cross section penis and penile block 
Table 2: Weight distribution $(N=336)$

\begin{tabular}{lcc}
\multicolumn{1}{c}{ Weight } & Number & Percentage \\
\hline $10-20 \mathrm{~kg}$ & 180 & 53.57 \\
$>20-30 \mathrm{~kg}$ & 105 & 31.25 \\
$>30 \mathrm{~kg}$ & 51 & 15.7 \\
Total & 336 & 100 \\
Mean weight: 13.4 kg & & \\
\hline
\end{tabular}

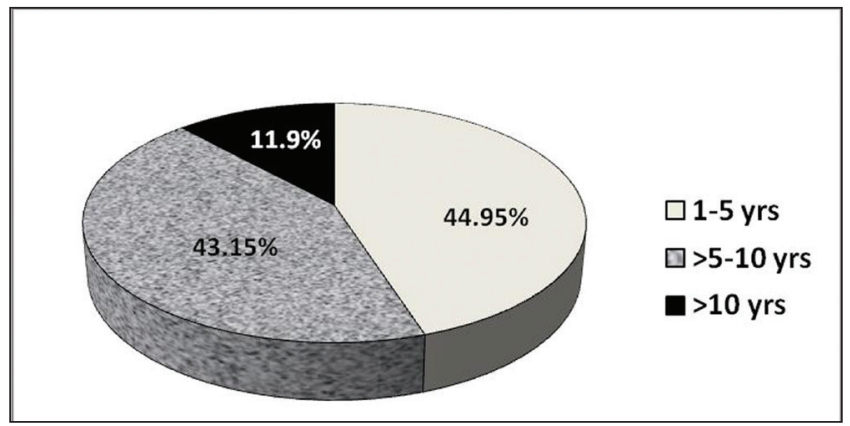

Figure 2: Age distribution according to the percentage

Table 3: Complications $(N=336)$

\begin{tabular}{lcc}
\multicolumn{1}{c}{ Complications } & Number & Percentage (\%) \\
Systemic & - & - \\
- Laryngospasm & - & - \\
- Cyanosis & - & - \\
- Convulsion & - & - \\
- Vomiting & 7 & $2.08 \%$ \\
- Cough & 10 & $2.98 \%$ \\
- Slight fall of $\mathrm{PaO}_{2}$ & & \\
Local & 11 & $3.27 \%$ \\
- Subcutaneous hematoma & 5 & $1.49 \%$ \\
- Incomplete block & 2 & $0.59 \%$ \\
- Urethral puncture & 2 & $0.59 \%$ \\
- Accidental injection in & & \\
$\quad$ corpus cavernosum & & \\
\hline
\end{tabular}

\section{DISCUSSION}

Circumcision is a minor surgery but a very painful procedure. Our aim is to give safe and low-cost anesthesia. Patient will not respond to pain during operation and will have a painfree early recovery without any hallucination or restlessness. Use of intravenous Ketamine alone produces analgesia but may cause undue muscle movement and hallucination during recovery. ${ }^{5}$ The incidence can be reduced by giving IV barbiturates or diazepam. ${ }^{6}$ Combinations of reduced doses of Ketamine and TPS exhibited enhanced neuroprotection against NMDA-induced neurotoxicity. Hence, combinations of these two common IV anesthetics agents could be developed to protect the brain from ischemia. ${ }^{7}$ Recovery from sleep may be prolonged if doses of TPS exceed $10 \mathrm{mg} / \mathrm{kg}$. We used a total dose of $7.5 \mathrm{mg} / \mathrm{kg}$ and administered at three divided doses, so there was no significant respiratory depression or fall of $\mathrm{SpO}_{2}$. The recovery time after induction of anesthesia with IV TPS with those of children who have inhalational induction by 30 minutes after surgery had no difference in recovery score between the two groups. ${ }^{8}$ For penile block we used $0.5 \%$ bupivacaine $4-5 \mathrm{ml}$ or $0.5 \%$ bupivacaine plus $2 \%$ lignocaine that does not exceed doses of local anesthetics, so there is no local anesthetic related to systemic toxicity. Main complication was mechanical, due to needle puncture like subcutaneous hematoma, urethral puncture, accidental injection into corpus cavernosum. If one feels resistance during pushing means that the needle is not in right position. In such case, the needle should be withdrawn slightly. By using small dose of local anesthesia, the complication can be avoided. Five patients experienced pain during incision or clamping and it may be due to partial block and was managed by inhalation of gases $\left(\mathrm{N}_{2} \mathrm{O}\right.$ and halothane). There were two cases of urethral puncture diagnosed where the local anesthetic drugs came out through the urethra. This can be reduced by taking precaution during injection in the ventral aspect of the penis. In a comparative study between the caudal block and penile block, it was found that degree and duration of postoperative analgesia were similar in two groups. Penile block may afford longer duration of analgesia when bupivacaine is used and is free of undesirable effects that may be associated with caudal block (delayed mobilization, micturation vomiting and lower extremity numbness). ${ }^{9,10}$ Caudal block group had a higher incidence of motor block while penile group had none of those.

The drugs used in our study were less expensive than any other type of anesthesia for circumcision.

\section{CONCLUSION}

Circumcision with low dose intravenous Ketamine and TPS with penile block is a safe and cost-effective anesthetic technique. 


\section{REFERENCES}

1. Linda JR. Regional anesthesia and analgesia. In: Motoyama EK, Davis PJ, editors. Smith's anesthesia for infants and children. 6th ed. London: Mosby-yearbook Inc.; 1996. p. 404.

2. Navil FS, Charle BB. Pediatric regional anesthesia. In: George AG, editor. Paediatric anaesthesia. 3rd ed. New York: Churchill Livingstone; 1994. p. 305.

3. Claire CY, William EB. Innervation of the human glans penis. Journal of Urology. 1999; 161:97-102.

4. Greengrass RA. Peripheral nerve blocks. In: Morgan G, Mikhail M, Murray M editors. Clinical anesthesiology. 4th ed. New York: McGraw-Hill Companies Inc.; 2005. p. 356.

5. Vikers MD, Morgan M, Spencer PSJ, Read MS. Central nervous system depressants. In: Vikers MD, Morgan M, Spencer PSJ, Read MS, editors. Drugs in anesthetic practice and intensive care practice. 8th ed. Oxford Butterworth Heinemann; 1999. p. 105.

6. George AG. Pharmacology. In: George AG, editor. Paediatric anesthesia. 3rd ed. New York: Churchill Livingstone; 1994. p. 35.

7. Shibuta S, Varathan S, Mashimo T. Ketamine and thiopental sodium: individual and combined neuroprotective effects on cortical cultures exposed to NMDA or nitric oxide. Br J Anaesth. 2006;97(4):517-24.

8. Steward DJ. Outpatient pediatric anesthesia. Anesthesiology. 1975;43(2):268-76.

9. Sara CA, Lowry CJ. A complication of circumcision and dorsal nerve block of the penis. J Anaesth Intensive Care. 1985;13(1):79-82.

10. Margetts L, Carr A, McFadyen G, Lambert A. A comparison of caudal bupivacaine and ketamine with penile block for paediatric circumcision. Eur J Anaesthesiol. 2008;25(12):1009-13. 